\title{
Stylistic Variation in Multilingual Instructions
}

\author{
Cécile Paris* and Donia Scott \\ Information Technology Research Institute \\ University of Brighton \\ Lewes Road \\ Brighton BN2 4AT, UK \\ email: \{Cecile.Paris,Donia.Scott\}@itri.bton.ac.uk
}

\begin{abstract}
Instructional texts have been the object of many studies recently, motivated by the increased need to produce manuals (especially multilingual manuals) coupled with the cost of translators and technical writers. Because these studies concentrate on aspects other than the linguistic realisation of instructions - for example, the integration of text and graphics - they all generate a sequence of steps required to achieve a task, using imperatives. Our research so far shows, however, that manuals can in fact have different styles, i.e., not all instructions are stated using a sequence of imperatives, and that, furthermore, different parts of manuals often use different styles. In this paper, we present our preliminary results from an analysis of over 30 user guides/manuals for consumer appliances and discuss some of the implications.
\end{abstract}

\section{Introduction}

Instructional texts have been the object of many studies recently, with an emphasis on methods for integrating graphics and text, as in WIP (Wahlster et al., 1993) and COMET (Feiner and McKeown, 1990), for tailoring to the user (Peter and Rüsner, 1994), for generating purpose expressions in English (Vander Linden, 1993), for producing multilingual instructions, (e.g., Rösner and Stede, 1991), and for planning the appropriate referring expressions, (e.g., Dale, 1992). Most of

This work is partially supported by the Commission of the European Union Grant LRE-62009, the Engineering and Physical Sciences Research Council (EPSRC) Grant J19221, and by BC./DAAD ARC Project 293. Dr. Paris also gratefully acknowledges the support of the National Science Foundation Grant IRI-9003087. We would like to thank John Bateman, Richard Power and the anonymous reviewers for their useful conments.

*Dr. Paris is on leave from USC/Information Sciences Institute, 4676 Admiralty Way, Marina del Rey, C.A 90292 and the Computer Science Department of the University of Southern California. these systems produce only a sequence of steps necessary to accomplish a task (e.g., change the engine oil, replace a radio battery, cook butter bean soup).

One of the motivations for generating instructions automatically is the increased need to produce manuals, especially multilingual manuals, coupled with the cost of translators and technical writers. This is important not only for European manufacturers, who are required to produce manuals in all the languages of the European Union, but also for multinational companies, whose international sales are reported to constitute over half of their total sales. Given this motivation, then, producing the sequence of steps required to achieve a task is only part of the job: most user guides and manuals contain more than a simple sequence of steps to achieve a task. In our work, we are attempting to generate a more complete user guide, in several languages.

The emphasis of previous research on instructions has led to the almost exclusive use of one type of discourse structure (a sequence, reflecting the sequence of steps needed for a task), and one type of realisation (the imperative). We have found, however, that manuals can have different styles: not all instructions are stated in a sequence, using the imperative form. This would indeed lead to rather monotonous texts, texts with potentially the wrong interpersonal force (too many imperatives can be too forceful!), and instructions in which the relative importance of various steps might be lost. Furthermore, different parts of manuals often use different discourse structures and forms of realisation. In our work, we are investigating the range of "styles" in instructional manuals in different languages, and the relationship between stylistic variants and the global structure of the manual both within and between languages.

The work reported here is part of the DRAFTER and the GIST projects at the University of Brighton (Scott, 1993), which aim to generate instructional manuals in several languages 
and in different domains. We have analysed user guides in various languages, attempting to avoid translated manuals. This paper presents our preliminary results concerning the different styles and global structures that frequently occur within English and French manuals for consumer appliances.

Although our analysis so far does not provide conclusive results with respect to the relationships between stylistic variants, the global structures, and different languages, they suggest that it is important for a system to provide a range of styles of instructions. Our results also indicate directions for further analysis.

\section{Variation in instructions}

Instructions are aimed at conveying directions to perform a (set of) task(s). For example, we can have instructions for filling out a form, or for operating and repairing a device. We include in our definition of instructions activities related to the actions to be performed, such as installation (preparatory steps), maintenance and trouble-shooting, as well as warnings concerning the safe execution of the actions. Confining instructions solely to central actions to be performed is too restrictive as the above-mentioned aspects are also integral parts of carrying out a task safely and efficiently.

The most straightforward way to get a reader to perform a task is, of course, through the use of a sequence of imperatives. However, our analysis of a corpus of over 30 user manuals for consumer appliances reveals a variety of realisations for such directions, from imperatives to simple statements. Statements may, by some, be considered to be outside the scope of instructions. We do not hold to this: we have found numerous examples to support the view that statements are often implicit instructions. Consider, for example, the following instructions from English and French for using a insulated flask, taken from EMSA Thermos.

Filter coffee: Simply place the filter on your EMSA vacuum jug to prevent escape of aroma and temperature

Filtrage du café: Le café peut-être filtré directement dans le pichet. Le porte-filtres s'adapte parfaitement sur l'ouverture du pichet, évitant ainsi la perte et la dispersion de l'arôme du café.

Loose English Translation: Filtering of Coffee: The coffee can be filtered directly into the jug. Filter holders fit perfectly on the opening of the jug, thus preventing loosing the aroma of the coffee

Here we see that the English instructions to filter coffee is given as an imperative, whereas, in the French version, the user is provided with a description of the utensil, from which the directions can be derived.

The issue of style is of course not a new one: indeed, there are whole subfields of theoretical and computational linguistics devoted to it. Sometimes it is referred to as stylistics (e.g., Crystal and Davy, 1969; Ager, 1970; DiMarco, 1992), special languages (e.g., Sager et al., 1980), sublanguages (e.g., Kittredge and Lehrberger, 1982), conative function (e.g., Jakobson, 1960), registers (e.g., Halliday, 1973; Ghadessy, 1988; Bateman and Paris, 1989; Martin, 1992), or pragmatic effects (e.g., Hovy, 1988). It is thus not surprising that this linguistic feature also applies to instructions, although it has not been explicitly addressed so far.

The different styles in instructional manuals appear to be closely allied to the stance the writer takes towards the reader. For example, different stances are usually taken when providing a description and a waming. Although, in general, such stances can be a decision on the part of the writer (or speaker), in which case it can be referred to as a conative intention (Sager et al., 1980), in the case of instructional manuals, it is usually an institutional decision on the part of the product manufacturer or the technical writing company (this is often referred to as "house style"). Stances can indeed be exploited in manuals to project a specific company image (for example, your friendly local nuclear power plant). These stances are factors that professional technical authors and translators are taught to pay particular attention to when writing or translating instructions, since failure to do so will lead to instructions which, although technically and grammatically correct, have an unintended pragmatic force. Following Systemic Linguistic Theory (Halliday, 1978), we will refer to these stances as semantic meanings to be expressed, at the interpersonal level.

Semantic meanings lead to the inclusion of different types of information, different organisations of a text, and different expressions of the actions to be performed. For instance, with indirect commands "the addressee is treated as if they have the right to demur"; a choice of a direct command, on the other hand, "grants the addressee little or no discretion" (Hasan, 1988, p 24). They can even result in different typographical devices. This is why not all instructions are written as a sequence of steps in the imperative mode. Depending on the semantic meanings to be conveyed, the text can be quite different at both the discourse and realisation levels. From our text analysis, we have began to identify different meanings that can be conveyed in user manuals and their preferred realisations. We have noted that these meanings are not constant throughout an entire manual, but vary across sections. It is thus necessary to identify the different parts that make up manuals, the semantic meanings that can be expressed in the different sections, and the linguistic means available to express them. Furthermore, given our multilingual framework, we are also investigating whether the preferred linguistic means of realising these meanings differ across languages, and whether the preferred stance is likely to change across various languages, as suggested by Hervey and Higgins (1992), and for different target audiences. The work on DRAFTER and GIST is directly related to these issues.

\section{Semantic Meanings}

We have so far analysed over 30 manuals given to users when they buy consumer-oriented goods, such as coffee machines and camping stoves, in both French and English when available. These manuals are at least one page long and can be up to 10 to 20 pages. In conducting our analysis, we tried to identify the different attitudes expressed in the texts, their potential realisations, and the global structure of the texts.

We have identified four different stances that a manual can adopt and give examples of them in Figure 1: 
(1) Information Provision - from Dietrich self-cleaning enamel oven:

L'émail auto-nettoyant est de couleur brun foncé moucheté de blanc pour certaines pièces.

Loose English Translation: The self-cleaning enamel is dark brown, speckled with white on some parts.

(2) Information Provision - from HP LaserJet 4 Printer Installation Guide:

The optional 500-sheet paper tray assembly comes equipped with a tray housing and either a legal, letter, A4, and executive multi-size paper tray or a letter, A4, and executive multi-size paper tray. You may purchase replacement trays from your authorized HP dealer. The part number of the letter, A4 and executive multi-size paper tray is C2084B...

(3) Eulogy - from Sennheisser Headphones:

To wish to convince you of the superior quality of the dynamic open air headphone $\mathrm{HD} 40$ would be something of a paradox as you are by now already in possession of this product. However, the arguments for the HD 40 are in fact very convincing:

- High quality reproduction.

- Extremely comfortable thanks to very low weight.

- Problem-free connection by means of universal connector.

- Very flat storage space thanks to turntable driver elements.

(4) Directive - from Krupp Expresso Coffee Machine:

Do not use or put down the appliance on any hot surface (such as a stove hot-plate) or in the vicinity of an open gas flame.

(5) Directive - from Camping Stove: Camping Gaz International:

Utilisez toujours votre réchaud dans un endroit suffisamment aéré, sans l'envelopper dans un objet quelconque et pas trop prés de matières inflammables.

Loose English Translation: Always use your stove in a well ventilated place, without wrapping it in any object and not too close to flammable substances.

(6) Explanation - from Dietrich Oven:

To avoid heavy spittings on the sole plate, it is advisable to cover it with an aluminium foil.

(7) Explanation - from EMSA Thermos Attention: Pour éviter d'abimer le récipient en verre, ne remuez pas les boissons avec des cuillères métalliques. Loose English Translation: Warning: To avoid damage to the glass jug, do not stir drinks with metallic spoons.

Figure 1: Stances a manual can adopt 
- information provision: the text concentrates on the factual knowledge to be conveyed. This can be seen as augmenting the reader's knowledge about the artifact and/or the task.

- eulogy: the text emphasises the positive aspects of the product or "congratulates" the readers on their good choice of purchase.

- directive on how to perform a task: the reader is to achieve a task exactly as prescribed. Here, the rationale behind the prescriptions is not considered necessary

- explanation on the preferred means of achieving the task: the reader is given advice as to how to achieve a task, and an explanation as to why it should be done in the prescribed way. This provides opportunities for the reader to construct a mental model of the task or of the artifact.

We note that the choice of stance seems to be influenced by several factors, including safety, requirements for memorability (for example, there is no point going to great length to have the reader build up a mental model of the task if it is to be accomplished only occasionally and there are no damaging consequences involved), and the expected expertise of the readership.

\section{Information provision and eulogy}

On taking these two stances, writers show a strong preference for the use of simple active declaratives. However, while their expressions tend to coincide in many aspects, there are also clear differences in linguistic expression of these two attitudes. (The similarities may well arise because it is useful to the manufacturer for eulogies about the product to be interpreted as factual information.)

When a eulogy is given, many attributes (qualifiers) tend to be included. They are realised as very positive adjectives and as superlatives. For further emphasis, consequences of a specific attribute are often provided, or examples are given. The type of language used to express this semantic meaning is similar to that used in advertising (Toolan, 1988).

Examples of texts in these categories are shown in $(1,2,3)$ of Figure 1. The texts in (1) and (2) are purely informative: the first provides information about the colour of the enamel inside the stove, the second about the printer paper tray. (3) is more of a eulogy, explicitly employing very favourable qualifiers, to convey the superior attributes of the product: high-quality reproduction, extreme comfort, etc.

\section{Directive}

The core function of instructions is to get users to perform (or avoid) specific actions. The most straightforward way of conveying this meaning is to provide directives: the reader is told to (or not to) do some action(s). The concern is not that the reader knows necessarily why this action should or should not be performed, but simply to have him or her follow the directive. The text asserts the authority of the writer (or the company) over the reader and leaves no choice to the reader to demur. Strongly directive speech acts (Sager et al., 1980) such as order or prohibit are used. An explanation of the order (or prohibition) is rarely given (in that the reader has no way of knowing the rationale behind the need to perform or avoid the prescribed action). This is illustrated in $(4,5)$ of Figure 1. In these instructions, the reason for performing (or avoiding) the action is not provided: i.e., no reason is given for why the appliance should not be put on a hot surface, or why the stove should be used in a well ventilated area. The reader is expected simply to follow the "directive. A setting or a condition for the action (e.g., when $\mathrm{X}$ happens, do $\mathrm{Y}$ ), is provided as well if necessary.

These strong directive speech acts can be realised in a number of ways, depending on the distance to be put between the reader and the writer (or the company) - this might also be seen as a matter of how personal/impersonal the author wishes to be:

- little distance - the writer directly addresses the reader: use of imperatives (or infinitives, in French), as in (1) in Figure 2.

- some distance - the writer addresses the reader but there is no strong involvement: use of the modal "must" ("devoir", possibly accompanied with an adverb, capitalised or embolded to carry extra force. This is illustrated in (2) of Figure 2.

- great distance - the order is given without addressing the reader: use of the passive (the device must not...), or employing verbs which require the object to become the syntactic subject, together with an adverb for emphasis. Examples are given in (3) of Figure 2.

In all cases, stronger emphasis on the directive can be given by including terms such as "never" or "under no circumstance", as part of the sentence or even as a separate sentence, as illustrated in (4) of Figure 2. Although these forms are available in both languages, our data so far show a predominance of the first category (the straight imperative) for English, and a much more equal distribution among the categories in French.

\section{Explanation}

Instructions sometimes have a tutorial aspect: it is then not enough simply to get the user to perform an action; there is also an attempt to get the user to understand why the action should be performed in the prescribed way, and why a specific action contributes to an overall goal. In this case, the rationale behind the directive is provided, explaining why the action is necessary or relating it to goals the reader is expected to have. More information related to the step to be performed/avoided is included, as shown in $(6,7)$ of Figure 1. Like the directive meaning, the text asserts the authority of the writer (or the company) over the reader. This time, however, the text now leaves some choice to the reader as to whether to proceed and/or provides a justification to the reader of why the action is requested, so that it is not interpreted as an order. This meaning is often expressed through the use of weakly directive speech acts (Sager et al., 1980), such as recommend or instruct.

As with the strong directives speech acts, a variety of syntactic forms can occur here in both French and English through the use of (1) an imperative accompanied with the 
(1) Little distance is put hetween writer and reader:

... grind the expresso coffee beans in a coffee mill set to grind "fine". (From Krupp Expresso Coffee Machine)

Lire très attentivement le mode d'emploi. (From DUROTHERM PLUS)

Loose English Translation: Read very carefully the manual.

(2) Some distance is put between writer and reader:

Pour une bonne sécurité, vous devez impérativement brancher votre appareil sur une prise de courant avec terre correspondant aux normes électriques. (From: Four Moulinex)

Loose English Translation: For safety, you must absolutely plug your device in an earthed socket.

After recording your OGM, you must leave the cassette tape in place. (From Dialatron Answering Machine).

To this end, the brewing sieve MUST first be unscrewed from the brewing head. (From Krupp Expresso Coffee Machine)

(3) Great distance is put between writer and reader :

The gas flame must heat only the bottom of the pan. (From DUROTHERM PLUS)

La flamme ne doit pas pas lécher les bords de l'ustensil. (From DUROTHERM PLUS):

Loose English Translation: The flame must not lick the sides of the device.

(4) Employing an adverb for stronger emphasis:

Never dip the appliance into water. (From Krupp Expresso Coffee Machine).

Utilisez une brosse a poils souples pour éliminer les miettes carbonisées. JAMAIS UN CHIFFON HUMIDE. (From: Four Moulinex)

Loose English Translation: Use a soft brush to get rid of burnt crumbs. NEVER A WET CLOTH.

Figure 2: Expressing strong directives

reason for the directive, or prefaced by some factual information which explains the directive; (2) an impersonal directive, such as "it is (not) advisable to..." (il est dé/conseillé $d e . .$. "), with the justification for the action, and sometimes with an emphatic adverb (e.g., "strongly"); (3) formulae such as "it is appropriate to" (il convient de, il y a lieu de), "it is recommended that" (il est recommendé), "act is/will be recommended" or the passive voice and the modal "should" (devoir). This choice once again depends on how strong, polite and indirect the writer wishes to be with respect to the reader. We give examples of the two extremes in Figure 3.

\section{Summary}

We have just outlined the different semantic meanings that seem to be conveyed in French and English instructional texts. The categorisation given above is still crude and requires further distinctions to account for the apparent overlap between some of the categories. For example, the following text is right now categorised as both an infonnation provision and a eulogy:

Le four à émail auto-nettoyant se différencie du four a émail normal par le fait que pendant la cuisson, les projections de corps gras sont détruites dès qu'elles arrivent au contact des parois chaudes. Le nettoyage du four est ainsi supprimé dans la plupart des cas. (From Dietrich self-cleaning enamel oven)

Loose English Translation: The self-cleaning enamel oven is different from normal enamel ovens, because fat splashes during cooking are eliminated on contact with the hot walls. Cleaning the oven is thus unnecessary in most cases.

Finer distinctions have already been made for other genres (e.g., Hasan, 1988; Martin, 1992). We are currently investigating the appropriate mappings between their results and our data in order to derive the necessary refinement.

Having identified the different meanings that can be expressed in instructional texts, we now turn to the text as a whole, identifying its global structure and the relationship between parts of the global structure of the manual and their preferred stance.

\section{A Global Structure}

Given our desire to generate user manuals automatically, we analysed the texts to see if they followed some global discourse structure as to what information was presented to the user, and what stance was taken at each point. We have found that the manuals were organised around several main parts:

- general information about the product 
Direct:

To prevent unnecessary damage to the container avoid using abrasive materials or sharp utensils when cleaning. (From Stewart Food Storage Containers)

Lisez attentivement cette notice: elle vous permettra d'en obtenir le meilleur service pour votre plus grande satisfaction. (From Camping Stove: Camping Gaz International)

Loose English Translation: Carefully read this notice: it will allow you to obtain the best results to your greatest satisfaction.

\section{Indirect:}

The milk should be well chilled. (From Krupp Expresso Coffee Machine).

... on ne devrait ajouter les épices qu'apres le processus de cuisson à l'étouffee. (From DUROTHERM PLUS)

Loose English Translation: ... one should add the spices only after the dish is cooked

Figure 3: Expressing weak directives

- general safety advice, warnings concerning specific actions

- installation of the device, or preparatory steps

- use

- maintenance, directions for care

- trouble-shooting and potential problems

Some manuals contain all these parts, each clearly indicated. This is not always the case, however, and the information corresponding to these parts might be interleaved, especially when space is a problem and the writers do not want to explicitly have a section for each information-type. For example, potential problems and warnings related to a specific step in a procedure might occur immediately after the step is given. ${ }^{1}$

The writer can potentially take a different stance towards the reader in each part of the manual. For lack of space, we will present only our results for parts pertaining to general information and safety. We will summarise the results for the other sections. We will not provide further examples here. Instead, we will refer to examples already given when possible.

\section{General Information}

This part of the manual tends to contain the following type of information:

- thanks for buying the product;

- description of the product, its advantages, and list of parts (often with accompanying diagrams).

- conditions for the warranty (or lack of)

Here, a general description of the artifact is given, often after a short paragraph thanking the buyer. Two stances appear to be appropriate for this description: information provision and eulogy. When information provision is chosen, the text either presents mainly attributes or is structured along the lines of one of the schemas defined in McKeown (1985). It can also contain a list of parts accompanied with diagrams.

\footnotetext{
${ }^{1}$ Note, however, that information from these major parts of a manual cannot be mixed randomly. This will not be discussed here.
}

When eulogy is chosen, although the text appears to be mainly informative, with the use of declarative sentences which describe the object, a large number of attributes (qualifiers) - especially attributes judged to be important to the reader - and superlatives are employed, and the product is described as being unique. While a description might be provided, it is equally common to find a list of the product's major attributes/advantages, one at a time, sometimes together with the consequence of a specific attribute (in terms of a user's goal) or with explicit examples.

In English manuals, this part is mostly for information provision. In French manuals, however, both forms appear frequently.

\section{Information about safety}

This part includes wamings, general safety advice, and crucial steps to be performed (either to accomplish the task or to obtain better results). It sometimes also contains a paragraph about reading the instructions. Our data show that the stance taken in this part can be a directive, as illustrated in (4) of Figure 1, or an explanation, as in (6) of Figure 1.

Taking the explanation stance here appears more prevalent in French than in English. Furthermore, in French, it is also possible to write this part of the manual as information provision (from which the reader can infer what must be done). For example, a specification of the conditions under which a product will be operational are given, and the reader is expected to make sure these conditions are achieved.

Explicit headings, explicit examples, lay-out (e.g., a framed box) and typography can be employed to signal further the importance of an advice or a waming. When warnings are not stated in an explicit section, but appear instead after the relevant action/step, they are most often introduced with the header Important, Warning, or Note, or are given in bold face.

\section{Summary of results for the remaining sections}

Preparatory step or installation: Information on how to install the device, or about various steps which have to be performed before the first use is provided. 


\section{CLEANING INSTRUCTIONS FOR YOUR STEAKMAKER "LA COTTA"}

The main value of the Steakmakers "La Cotta", whatever the type and size, is to absorb all the noxious fats of meats, which in this way, becomes tasty, healthy, easily digestible.

The Steakmakers have a highly absorbing power, since they are made of a special volcanic refractory material, and after a lot of times you have cooked with them they will fill up with fats and acids (it goes without saying that the saturation time depends also on meat, which may be more or less fat).

At this point fat starts seeping outside, drawn and eliminated by the heat of the stove, allowing this natural filter to keep on absorbing and filtering.

Figure 4: Wrong choice of conative force - Steakmaker "La Cotta"

Use: The steps (actions) that must be performed for the reader to use the artifact and achieve various tasks are given. Depending on the object under consideration, it is organised around the task to be achieved, or around specific elements of the object (which can be used to achieve a specific task).

Clean, Care and Maintenance: This is where the author tells the reader how to clean and care for the artifact.

In the three parts above, directive and explanation are appropriate. In our corpus, English manuals tend to be written more with the directive stance, while in French manuals, these two stances are almost equally likely. Finally, as in the case of the section about safety, the information provision stance is sometimes found in these sections of French manuals.

Trouble shooting: The point of this part is to help the reader identify the source of a problem and provide information about what might go wrong if a step is not properly performed. Actions to be performed are provided, together with the conditions under which they are appropriate, and solutions to problems. The stance is usually directive (actions allowing the reader to identify the source of the problems are given). In French, the stance can also be an explanation or information provision; this is however rare in English.

\section{Discussion}

In our work on generating multilingual instructions, we have found that there are often multiple ways to provide instructions, each taking a different stance towards the reader. Always adopting one realisation form leads to monotonous text. Clearly, computational systems should be able to generate the variations found in texts.

It has been suggested in sociolinguistics that there is a strong correlation between language and behaviour. One aspect of this is the relationship between "ways of talking and ways of learning" (Hasan, 1988). This is relevant to instructions, where the aim is to get the reader to learn how to perform a task. Learning and memory are not disconnected cognitive processes, and we suspect that memorability has a role to play in the chosen stance for a specific part of a manual. For example, the instructions for installation are likely to be followed only once whereas those for general use could be executed daily. The former need not be remembered, whereas the latter must be learnt. This may well be a motivating factor in the choice of stance for the various parts of the manual.
If this is the case, then, the need to produce the range of instructions found in text is no longer a matter of stylistics only, but becomes critical to avoid generating instructions in which the relative importance of various steps might be lost because all steps are expressed in the same way.

Clearly, instructions generated with the wrong stance can lead readers to misinterpret the importance of the steps presented in various parts of the text. Consider for example the text shown in Figure 4, translated from Italian. Because eulogies cannot be used for giving directives, on reading this, most readers (or at least ourselves!) are likely to understand that the pan does not need any cleaning, thanks to its properties. Lo and behold, in the text that follows - which is laid out in a way that suggests that its content is secondary to that which precedes it - we leam that cleaning the pan is critical for avoiding toxification, and steps to achieve this are given. Because of the eulogy stance taken here, we are not expecting to be told that the pan actually needs cleaning (even though the header provides a strong clue). As a result, the instructions for cleaning the pan may be overlooked. We will be investigating issues pertaining to usability in a separate phase of our projects, related to the development of evaluation criteria for instructions.

Our data further suggest that the mappings from stance to realisation is not language independent. This observation reinforces our belief that multilingual generation will lead to better texts than machine translation will, because a straightforward translation from one language to another might result in text that is awkward or which has the wrong pragmatic force. In addition, the choice of stance itself could also be culturally motivated. If this is indeed the case, then only through multilingual generation can a text with the appropriate stance be produced automatically.

In this paper, we raise the issue of the importance of stylistic variation in instructions, and pose a number of questions that must be addressed. Our analysis has provided guidelines for proceeding with a comprehensive study of this feature of naturally-occuring instructions. Our first step is to refine our analysis to provide further distinctions in the semantic meanings and to identify more clearly their associated realisation. This analysis will apply to instructions such as the ones discussed here as well as to those for other domains (e.g., software documentation, instructions for administrative procedures).

We will be using our results in a text generation system to 
guide text planning and realisation in several languages. We intend to make use of these semantic meanings both by adding further constraints on the discourse strategies employed during text planning, and by constraining the deployment of the available linguistic resources during generation, using notions such as register-controlled generation (Bateman and Paris, 1991).

\section{References}

Ager, D. (1970). Styles and registers in contemporary French. University of London Press, London.

Bateman, J. A. and Paris, C. L. (1989). Phrasing a Text in Terms the User Can Understand. In Proceedings of the Eleventh International Joint Conference on Artificial Intelligence, pages 1511-1517, Detroit, Michigan.

Bateman, J. A. and Paris, C. L. (1991). Constraining the deployment of lexicogrammatical resources during text generation: towards a computational instantiation of register theory. In Ventola, E., editor, Functional and Systemic Linguistics: Approaches and Uses, chapter 5, pages 81-106. Mouton de Gruyter.

Crystal, D. and Davy, D. (1969). Investigating English Style. Longmans, London.

Dale, R. (1992): Generating Referring Expressions: Constructing Descriptions in a Domain of Objects and Processes. MIT Press, Cambridge, MA.

DiMarco, C. and Hirst, G. (1993). A Computational Theory of Goal-Directed Style in Syntax. Computational Linguistics, 19(3):451-499.

Feiner, S. K. and McKeown, K. R. (1990). Coordinating text and graphics in explanation generation. In Proceedings of the National Conference on Artificial Intelligence, pages 442-449, Boston, MA.

Ghadessy, M., editor (1988). Registers of Written English: situational factors and linguistic features. Frances Pinter, London.

Halliday, M. A. K. (1973). Explorations in the Functions of Language. Edward Amold, London.

Halliday, M. A. K. (1978). Language as social semiotic. Edward Amold, London.

Hasan, R. (1988). Meaning in Sociolinguistic Theory. Presented at the First Hong Kong Conference on Language and Society.

Hervey, S. and Higgins, I. (1992). Thinking Translation. Routledge, London, UK.

Hovy, E. H. (1988). Generating Natural Language Under Pragmatic Constraints. Lawrence Erlbaum, Hillsdale, New Jersey.

Jakobson, R. (1960). Linguistics and poetics. In Sebeok, $\mathrm{T}$. A., editor, Style in Language, pages 350-377. MIT Press, Cambridge, MA.

Kittredge, R. and Lehrberger, J., editors (1982). Sublanguage: Studies of language in restricted semantic domains. de Gruyter, Berlin and New York.
Martin, J. R. (1992). English text: systems and structure. Benjamins, Amsterdam.

McKeown, K. R. (1985). Text Generation: Using Discourse Strategies and Focus Constraints to Generate Natural Language Text. Cambridge University Press, Cambridge, England.

Peter, G. and Rösner, D. (1994). User-Model-Driven Generation of Instructions. User Modeling and User Adapted Interaction.

Rösner, D. and Stede, M. (1991). Towards the Automatic Production of Multilingual Technical Documents. Technical Report FAW-R-91022, Research Institute for Applied Knowledge Processing (FAW), Ulm, Germany.

Sager, J. C., Dungworth, D., and McDonald, P. F. (1980). English Special Languages. Brandstetter Verlag, Wiesbaden, Germany.

Scott, D. R. (1993). Generating Multilingual Instructions. Contribution to the panel on "Instructions: Language and Behavior". In Proceedings of the International Joint Conference on Artificial Intelligence (IJCAI-93), Chambery, France.

Toolan, M. (1988). The Language of Press Advertising. In Ghadessy, M., editor, Registers of Written English: situational factors and linguistic features, pages 52-64. Frances Pinter, London.

Vander Linden, K. (1993). Speaking of Actions: Choosing Rhetorical Status and Grammatical Form in Instructional Text Generation. $\mathrm{PhD}$ thesis, University of $\mathrm{Col}$ orado. Available as Technical Report CU-CS-654-93.

Wahlster, W., André, E., Finkler, W., Profitlich, H.-J., and Rist, T. (1993). Plan-Based Integration of Natural Language and Graphics Generation. Artificial Intelligence Journal, (63):387-427. Also a DFKI Research Report RR-93-02. 